\title{
PERENCANAAN LOKASI PENGEMBANGAN PERKEBUNAN KARET RAKYAT DI KABUPATEN MANDAILING NATAL, PROVINSI SUMATERA UTARA
}

\section{Planning of Development Location of Rubber Smallholding in Mandailing Natal Regency, North Sumatera Province}

\author{
Hadijah Siregar1), Santun Risma Pandapotan Sitorus ${ }^{2}{ }^{*}$, Atang Sutandi2)
}

\begin{abstract}
1)Dinas Kehutanan dan Perkebunan Kabupaten Mandailing Natal, Komplek Perkantoran Payaloting, Panyabungan, Kabupaten Mandailing Natal, Sumatera Utara 22978

2)Departemen Ilmu Tanah dan Sumber Daya Lahan, Fakultas Pertanian IPB, Jl. Meranti Kampus IPB Dramaga,
\end{abstract} Bogor 16680

\begin{abstract}
Development of preminent commodity of rubber is one of Mandailing Natal Regency government's strategy to improve society prosperity. To support the mentioned things, this research is conducted with purpose: (1) determining suitability location for the development of rubber plantation based on physical aspects of land and (2) analysing and formulating the directive of rubber smallholding potential development policy in Mandailing Natal Regency. The land suitability analysis spasial overlay materials and descriptive analysis were implements. The research results showed that acreage of potential area for the development of rubber plantation in Mandailing Natal Regency was 460,849 ha (70.4\%). The location and acreage which could be to recommend for the development of rubber plantation in Mandailing Natal Regency based on location potential and relevant government regulations had been mentioned, and would cover 201,875 ha (30.8\%).
\end{abstract}

Keywords: Land evaluation, potential location, recommended development, rubber smallholding

\begin{abstract}
ABSTRAK
Pengembangan perkebunan karet merupakan salah satu strategi yang cukup realistis bagi pemerintah Kabupaten Mandailing Natal dalam meningkatkan perekonomian dan kesejahteraan masyarakatnya. Untuk mendukung hal tersebut penelitian ini bertujuan untuk: (1) menentukan lokasi yang berpotensi untuk pengembangan tanaman karet rakyat berdasarkan aspek fisik lahan dan (2) menganalisis dan menyusun arahan kebijakan pengembangan perkebunan karet rakyat di Kabupaten Mandailing Natal. Metode analisis dilakukan berdasarkan penentuan kesesuaian lahan, analisis spasial, dan analisis deskripsi. Hasil penelitian menunjukkan bahwa sebagian besar lahan di Kabupaten Mandailing Natal sesuai untuk budidaya tanaman karet yaitu seluas 460,849 ha (70.4\%). Lokasi dan luas areal pengembangan perkebunan karet rakyat di Kabupaten Mandailing Natal berdasarkan potensi lokasi dan peraturan pemerintah terkait telah dikemukakan, dan dapat diarahkan pada lahan seluas 201,875 ha $(30.8 \%)$.
\end{abstract}

Kata kunci: Evaluasi lahan, lokasi potensial, pengembangan rekomendasi, karet rakyat

\section{PENDAHULUAN}

Indonesia merupakan negara eksportir karet terbesar kedua di dunia setelah Thailand. Indonesia memiliki areal perkebunan karet terluas di dunia namun produktivitasnya masih rendah. International Rubber Study Group (IRSG) meramalkan bahwa pada tahun 2020 konsumsi karet dunia akan mencapai 10.9 juta ton dan produksi dunia mencapai 10.9 juta ton sehingga terdapat surplus 54,000 ton (Ditjenbun, 2009). Dalam rangka penguatan sektor perkebunan di Indonesia, pemerintah telah mencanangkan program revitalisasi perkebunan yakni suatu upaya percepatan pengembangan perkebunan rakyat melalui perluasan, peremajaan dan rehabilitasi tanaman perkebunan yang didukung kredit investasi perbankan dan subsidi bunga oleh pemerintah dengan tiga komoditas yaitu kelapa sawit, karet dan kakao (Ditjenbun, 2007).

Berdasarkan data dan posisi yang cukup strategis tersebut, karet diharapkan menjadi salah satu penggerak kebangkitan ekonomi melalui peningkatan produksi yang akan meningkatkan ekspor karet. Hal ini akan menjadi peluang yang baik bagi Indonesia untuk mengekspor karet dan hasil olahan industri karet yang ada di Indonesia ke negara-negara lainnya. Luas areal perkebunan karet Indonesia sekarang ini mencapai 3.52 juta ha yang terdiri atas $85 \%$ perkebunan rakyat dan sisanya perkebunan besar swasta dan badan usaha milik negara dengan produksi sekitar 3 juta ton dan menyerap sedikitnya 2.30 juta tenaga kerja. Luas perkebunan karet Indonesia merupakan yang 
terluas di dunia disusul Thailand seluas 2.76 juta ha. Pemulihan ekonomi akibat krisis global tahun 2007 menyebabkan permintaan karet juga meningkat. Diramalkan pada 2015 Indonesia dapat meningkatkan produksi dengan laju yang tinggi, sehingga dapat melampaui produksi Thailand (Ditjenbun, 2009).

Prospek karet alam akan baik selama ekonomi tumbuh dengan baik dan produksi tidak mengalami gangguan cuaca, sehingga pemerintah perlu membuat perencanaan yang matang dalam peremajaan dan pembukaan kebun karet baru. Peluang untuk menjadi produsen utama di dunia dimungkinkan, karena Indonesia mempunyai potensi sumberdaya yang sangat memadai untuk meningkatkan produksi melalui program revitalisasi perkebunan. Pengembangan komoditas karet di lahan kering dan kritis juga memberi kontribusi nyata dalam memelihara bahkan memperbaiki lingkungan. Di samping itu, pengembangan komoditas karet dalam bentuk agroforestry serta pemanfaatan kayu karet sebagai pengganti kayu dari hutan primer merupakan kontribusi lain perkebunan karet dalam konservasi lingkungan (Boerhendhy et al., 2003)

Kabupaten Mandailing Natal merupakan daerah dengan areal tanaman karet terluas di Propinsi Sumatera Utara. Berdasarkan data statistik, luas lahan yang diusahakan oleh masyarakat sampai tahun 2008 seluas 71,015 ha dengan produksi 34,615 ton (BPS Mandailing Natal, 2009).

Permasalahan utama yang dihadapi perkebunan karet rakyat adalah rendahnya produktivitas karet dan tingginya proporsi areal tanaman karet tua. Mempertimbangkan besarnya potensi pengembangan karet di Kabupaten Mandailing Natal dan dalam upaya penanganan permasalahan pengembangan karet, perlu dilakukan perencanaan untuk menghindari agar masyarakat tidak dirugikan dengan menanam tanaman karet di lokasi yang tidak sesuai dengan kriteria tumbuh tanaman (biofisik), aspek spasial (tata ruang) dan aspek ekonomi. Diperlukan arahan bagi masyarakat dalam memilih lokasi yang tepat untuk budidaya tanaman tersebut.

Pemilihan lokasi yang tepat akan menghasilkan produktivitas yang maksimal dan akan berkorelasi dengan keuntungan yang didapatnya, maka penelitian ini bertujuan untuk menentukan lokasi yang berpotensi untuk pengembangan tanaman karet rakyat berdasarkan aspek fisik dan menyusun arahan kebijakan pengembangan perkebunan karet rakyat di Kabupaten Mandailing Natal. Hasil penelitian diharapkan dapat menjadi masukan kepada Pemerintah Daerah dalam penyusunan kebijakan pengembangan perkebunan karet rakyat di Kabupaten Mandailing Natal.

\section{BAHAN DAN METODE}

\section{Pengumpulan Data}

Penelitian menggunakan data sekunder yang diperoleh di Kabupaten Mandailing Natal. Data Sekunder diperoleh dari Badan Pusat Statistik, Dinas Kehutanan dan Perkebunan, Bappeda di Kabupaten Mandailing Natal dan Dinas/Instansi terkait lainnya.

\section{Teknik Analisis Data}

\section{Penentuan Lokasi Berpotensi untuk Pengembangan Karet Rakyat}

Penentuan lokasi yang berpotensi untuk pengembangan karet secara fisik dilakukan dengan mengoverlay peta kesesuaian lahan dalam skala 1:50,000 yang dibuat oleh Bappeda Kabupaten Mandailing Natal dengan peta administrasi Kabupaten Mandailing Natal skala 1:50,000 dengan SIG. Peta kesesuaian lahan tersebut merupakan hasil evaluasi kesesuaian lahan dengan menggunakan klasifikasi kesesuaian lahan (Hardjowigeno dan Widiatmaka, 2007; Sitorus, 2004).

\section{Arahan Kebijakan Pengembangan Perkebunan Karet Rakyat}

Penyusunan arahan pengembangan perkebunan karet rakyat di Kabupaten Mandailing Natal dilakukan secara spasial dan deskriptif. Peta arahan pengembangan perkebunan rakyat dibuat dengan mengoverlay peta kesesuaian lahan tanaman karet dengan peta penggunaan lahan sekarang (present land use), peta kawasan hutan (SK.44/Menhut-II/2005 tanggal 16 Februari 2005 tentang Penunjukan Kawasan Hutan di Wilayah Provinsi Sumatera Utara seluas $\pm 3,742,120$ ha), peta cadangan Hutan Tanaman Rakyat/HTR (SK.113/Menhut-II/2008 tanggal 21 April 2008 tentang Pencadangan Areal Hutan untuk Pembangunan Hutan Tanaman Rakyat seluas \pm 9,815 ha di Kabupaten Mandailing Natal) dan disesuaikan dengan RTRW (Rencana Tata Ruang Wilayah) Kabupaten Mandailing Natal (belum disahkan) serta mempertimbangkan Peraturan Pemerintah Republik Indonesia Nomor: 6 tahun 2007 jo Peraturan Pemerintah Nomor 3 tahun 2008 tentang Tata Hutan dan Penyusunan Rencana Pengelolaan Hutan serta Pemanfaatan Hutan dan Peraturan Menteri Kehutanan Nomor P.37/Menhut-II/2007 tentang Hutan Kemasyarakatan serta Peraturan Menteri Kehutanan Nomor P.49/Menhut-II/2008 jo nomor: P.14/Menhut-II/2010 tentang Hutan Desa serta UndangUndang Nomor 41 tahun 2009 tentang Perlindungan Lahan Pertanian Pangan Berkelanjutan (Tabel 1). Semua peta yang dioverlay berskala 1:50,000. 
Tabel 1. Penentuan arahan pengembangan perkebunan karet rakyat di Kabupaten Mandailing Natal

\begin{tabular}{|c|c|c|c|c|}
\hline RTRW & $\begin{array}{c}\text { SK Menhut } \\
\text { No.44/Menhut-II/2005 }\end{array}$ & Penggunaan lahan sekarang & $\begin{array}{l}\text { Kelas kesesuaian } \\
\text { lahan }\end{array}$ & Kategori \\
\hline \multirow[t]{3}{*}{$\mathrm{KB}$} & $\begin{array}{l}\text { Areal Penggunaan Lain } \\
\text { Hutan Produksi Tetap }\end{array}$ & $\begin{array}{l}\text { Kebun karet rakyat tua dan tidak produktif, padang rumput, } \\
\text { alang-alang, semak, kebun rakyat (ladang, kebun campuran) }\end{array}$ & $\mathrm{S} 1, \mathrm{~S} 2, \mathrm{~S} 3$ & Arahan \\
\hline & Hutan Produksi Terbatas & & $\mathrm{N} 1, \mathrm{~N} 2$ & Bukan arahan \\
\hline & & Sawah, areal terbangun (pemukiman), perkebunan besar & $\mathrm{S} 1, \mathrm{~S} 2, \mathrm{~S} 3, \mathrm{~N} 1, \mathrm{~N} 2$ & Bukan arahan \\
\hline KL & $\begin{array}{l}\text { Kawasan Suaka Alam } \\
\text { Hutan Lindung }\end{array}$ & Apapun jenis penggunaan lahan & $\mathrm{S} 1, \mathrm{~S} 2, \mathrm{~S} 3, \mathrm{~N} 1, \mathrm{~N} 2$ & Bukan arahan \\
\hline
\end{tabular}

KB = Kawasan Budidaya, KL = Kawasan Lindung.

Penentuan arahan potensi pengembangan perkebunan karet rakyat di Kabupaten Mandailing Natal dalam penelitian ini mempertimbangkan status kawasan hutan. Kawasan yang dipertimbangkan adalah kawasan hutan produksi sebagai kawasan budidaya kehutanan, sedangkan kawasan hutan suaka alam dan hutan lindung yang tujuannya untuk melindungi kelestarian alam tidak diarahkan untuk pengembangan karet. Lokasi-lokasi untuk tanaman pangan seperti penggunaan lahan sawah tidak akan diarahkan untuk pengembangan tanaman karet, hal ini sesuai dengan Undang-Undang Nomor 41 tahun 2009 tentang Perlindungan Lahan Pertanian Pangan Berkelanjutan.

Dalam peraturan-peraturan yang berhubungan dengan kehutanan tersebut disebutkan bahwa hutan produksi dapat dimanfaatkan menjadi hutan tanaman rakyat, hutan kemasyarakatan dan hutan desa. Hutan tanaman rakyat yang selanjutnya disingkat HTR adalah hutan tanaman pada hutan produksi yang dibangun oleh kelompok masyarakat untuk meningkatkan potensi dan kualitas hutan produksi dengan menerapkan silvikultur dalam rangka menjamin kelestarian sumberdaya hutan. Hutan kemasyarakatan adalah hutan negara yang pemanfaatan utamanya ditujukan untuk memberdayakan masyarakat setempat dan hutan desa adalah hutan negara yang dikelola oleh desa dan dimanfaatkan untuk kesejahteraan desa serta belum dibebani izin/hak.

Areal pengembangan karet rakyat dapat dilakukan di areal hutan produksi dengan tanaman karet yang berasal dari biji atau seedling atau bibit unggul yang sesuai, baik nantinya akan sebagai hutan kemasyarakatan, hutan desa atau hutan tanaman rakyat dengan pengelolaan agroforestry yang secara aspek lingkungan dapat melindungi kelestarian hutan. Arahan kebijakan pengembangan perkebunan karet rakyat di Kabupaten Mandailing Natal akan disusun secara deskriptif dengan pertimbangan peta arahan pengembangan perkebunan karet rakyat di Kabupaten Mandailing Natal, peraturanperaturan pemerintah serta mempertimbangkan arahan pengembangan wilayah Pemerintah Daerah Kabupaten Mandailing Natal. Kriteria penentuan arahan pengembangan perkebunan karet rakyat di Kabupaten Mandailing Natal dapat dilihat pada Tabel 1.

\section{HASIL DAN PEMBAHASAN}

\section{Persebaran Lahan Potensial Secara Fisik Untuk Tanaman Karet}

Secara spasial lokasi lahan berdasarkan kelas kesesuaian dapat dilihat pada Gambar 1. Dari peta kesesuaian lahan untuk tanaman karet diperoleh informasi bahwa sebagian besar lahan di Kabupaten Mandailing Natal sesuai untuk tanaman karet yaitu seluas 460,849 ha (70.4\%) dan lahan yang tidak sesuai seluas 193,693 ha $(29.6 \%)$. Secara aktual sebagian besar areal tergolong kelas Sesuai Marjinal (S3) yaitu seluas 421,387 ha (64.4\%) dan yang tergolong kelas Cukup Sesuai (S2) seluas 23,031 ha $(3.52 \%)$ dan lahan yang tergolong kelas Sangat Sesuai (S1) seluas 16,430 ha (2.51\%) untuk tanaman karet.

Lahan dengan kelas kesesuaian S1, S2 dan S3 pada setiap kecamatan di Kabupaten Mandailing Natal dengan luasan yang bervariasi (Tabel 2). Kecamatan dengan kelas kesesuaian S1 yang terbesar adalah kecamatan Siabu yaitu 5,915 ha. Lahan dengan kelas kesesuaian S2 adalah kecamatan Batahan yaitu seluas 5,326 ha. Kecamatan yang memiliki kelas kesesuaian lahan karet S3 ada di semua kecamatan dan yang terluas adalah Kecamatan Muara Batang Gadis yaitu seluas 153,857 ha.

\section{Arahan Kebijakan Pengembangan Perkebunan Karet Rakyat di Kabupaten Mandailing Natal}

\section{Persebaran Arahan Lokasi Pengembangan Kebun Karet Rakyat}

Lokasi arahan pengembangan tanaman Karet dibagi menjadi beberapa prioritas arahan dengan mempertimbangkan ketentuan arahan pengembangan perkebunan karet rakyat di Kabupaten Mandailing Natal (Tabel 1), status areal kawasan hutan, kelas kesesuaian lahan, penggunaan lahan saat ini. Lahan kelas S1 dan S2 dengan penggunaan lahan padang rumput, alang-alang, semak dan tegalan di luar kawasan hutan yang sesuai untuk pertanaman Karet sudah tidak tersedia lagi di Kabupaten Mandailing Natal dan tanaman karet tua tidak terdapat di areal kesesuaian lahan S1, sehingga lahanlahan tersebut tidak dipertimbangkan dalam penentuan prioritas arahan pengembangan karet rakyat di Kabupaten Mandailing Natal. Areal HTR yang telah ditetapkan semuanya berada pada kelas kesesuaian lahan S3. 
Pembagian prioritas arahan pengembangan dapat dilihat pada Tabel 3 .

Persebaran arahan lokasi pengembangan tanaman Karet disusun dengan pertimbangan Tabel 1 dan 3. Secara spasial dapat dilihat pada Gambar 2. Lahan yang berpotensi untuk pengembangan tanaman karet di
Kabupaten Mandailing Natal seluas 201,875 ha atau $30.8 \%$ dari luas wilayah Kabupaten Mandailing Natal. Kecamatan dengan lahan berpotensi terluas adalah Kecamatan Muara Batang Gadis seluas 71,406 ha (10.9\%), diikuti dengan Kecamatan Natal seluas 17,993 ha (2.75\%) dan Kecamatan Batahan seluas 12,691 ha (1.94\%).

Tabel 2. Luasan kelas kesesuaian lahan aktual untuk tanaman karet pada masing-masing kelas kesesuaian lahan untuk tanaman karet di Kabupaten Mandailing Natal

\begin{tabular}{|c|c|c|c|c|c|c|c|}
\hline \multirow{2}{*}{ No } & \multirow{2}{*}{ Kecamatan } & \multicolumn{4}{|c|}{ Kelas Kesesuaian (ha) } & \multicolumn{2}{|c|}{ Jumlah } \\
\hline & & N1 & $\mathrm{S} 1$ & $\mathrm{~S} 2$ & S3 & Hektar & $\%$ \\
\hline 1 & Batahan & 1,865 & 2,251 & 5,327 & 24,949 & 34,392 & 5.25 \\
\hline 2 & Batang Natal & 51,464 & - & - & 27,006 & 78,471 & 11.99 \\
\hline 3 & Bukit Malintang & 1,916 & 439 & 337 & 3,017 & 5,710 & 0.87 \\
\hline 4 & Hutan Bargot & 1,337 & 61.0 & 648 & 8,264 & 10,311 & 1.58 \\
\hline 5 & Kotanopan & 9,746 & - & 118 & 19,374 & 29,239 & 4.47 \\
\hline 7 & Lingga Bayu & 11,711 & 545 & 710 & 10,352 & 23,319 & 3.56 \\
\hline 8 & Muara Batang Gadis & 18,024 & 1,254 & 2,481 & 153,857 & 175,617 & 26.8 \\
\hline 9 & Muarasipongi & 4,871 & - & - & 8,250 & 13,122 & 2.00 \\
\hline 10 & Naga Juang & 1,698 & 521 & 187 & 2,374 & 4,781 & 0.73 \\
\hline 11 & Natal & 23,512 & 4,292 & 1,097 & 50,406 & 79,308 & 12.1 \\
\hline 12 & Pakantan & 473 & - & 351 & 9,863 & 10,687 & 1.63 \\
\hline 13 & Panyabungan & 9,398 & - & 2,601 & 12,192 & 24,192 & 3.70 \\
\hline 14 & Panyabungan Barat & 1,401 & - & 648 & 5,668 & 7,717 & 1.18 \\
\hline 16 & Panyabungan Timur & 22,869 & - & 276 & 11,984 & 35,129 & 5.37 \\
\hline 17 & Panyabungan Utara & 1,809 & 670 & 1,035 & 2,136 & 5,650 & 0.86 \\
\hline 18 & Puncak Sorik Marapi & - & - & 113 & 4,814 & 4,927 & 0.75 \\
\hline 19 & Ranto Baek & 14,712 & - & 255 & 3,398 & 18,365 & 2.81 \\
\hline 20 & Siabu & 10,103 & 5,915 & 1,485 & 11,579 & 29,083 & 4.44 \\
\hline 21 & Sinunukan & - & 480 & 177 & 13,449 & 14,106 & 2.16 \\
\hline 22 & Tambangan & 6 & - & 734 & 13,569 & 14,309 & 2.19 \\
\hline \multirow[t]{2}{*}{23} & Ulu Pungkut & 6,184 & - & 1,992 & 18,269 & 26,446 & 4.04 \\
\hline & Jumlah & 193,693 & 16,430 & 23,031 & 421,388 & 654,542 & 100 \\
\hline
\end{tabular}

Tabel 3 . Pembagian prioritas arahan pengembangan karet rakyat di Kabupaten Mandailing Natal

\begin{tabular}{lcc}
\hline $\begin{array}{c}\text { Prioritas lokasi } \\
\text { arahan }\end{array}$ & $\begin{array}{c}\text { Kelas } \\
\text { kesesuaian }\end{array}$ & \multicolumn{1}{c}{ Penggunaan lahan dan status/ketersediaan } \\
\hline Prioritas I & S3 & Padang rumput, alang-alang, semak belukar di luar kawasan hutan \\
\hline Prioritas II & S2 & Kebun karet tua di luar kawasan hutan \\
\hline Prioritas III & S3 & Kebun karet tua di luar kawasan hutan, areal yang telah ditetapkan sebagai areal HTR \\
\hline Prioritas IV & S1,S2,S3 & $\begin{array}{l}\text { Padang rumput, alang-alang, semak belukar, karet tua di dalam kawasan Hutan Produksi, } \\
\text { kebun rakyat di APL (Areal Penggunaan Lain) dan HP (Hutan Produksi) }\end{array}$ \\
\hline
\end{tabular}




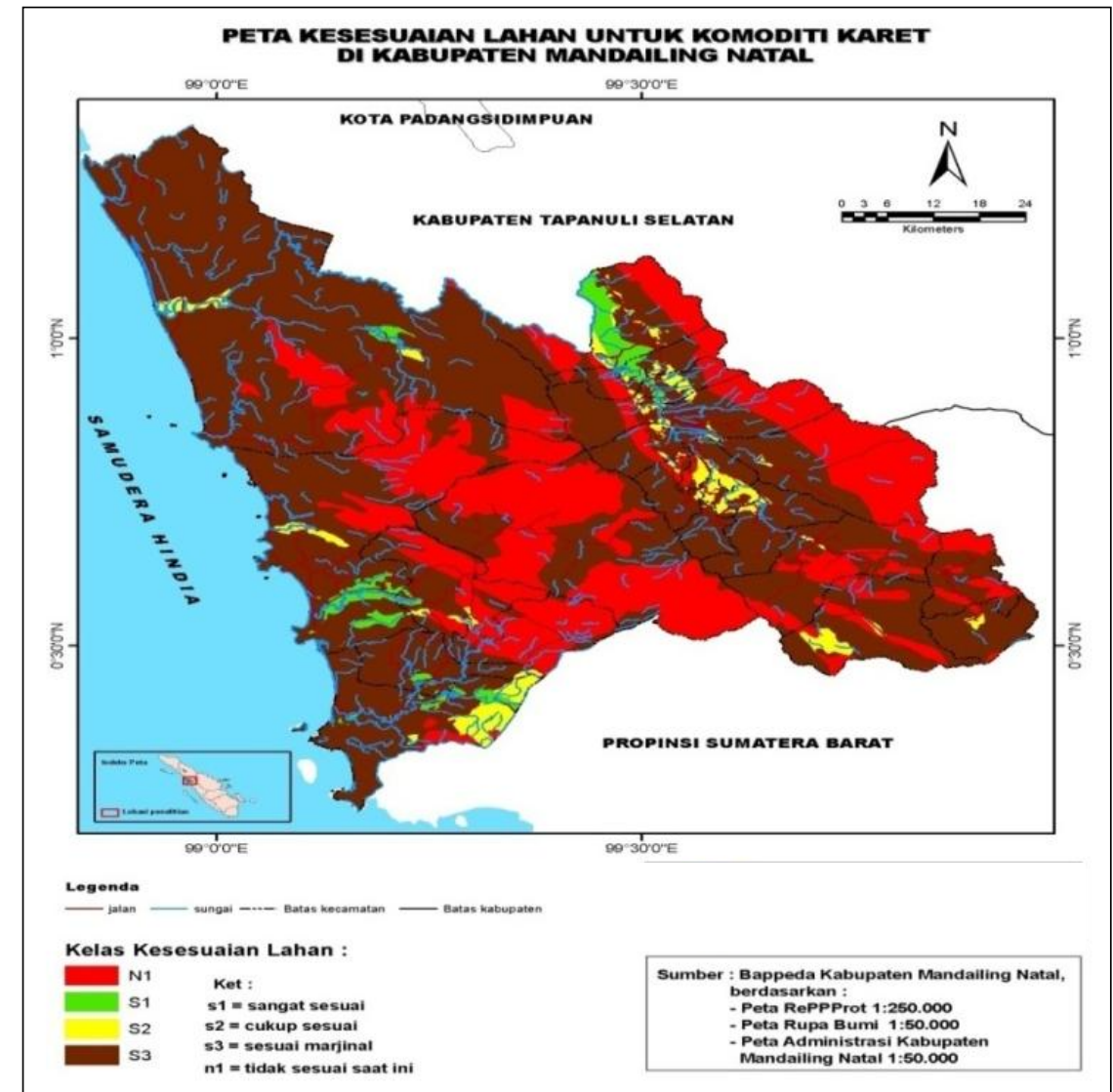

(a)

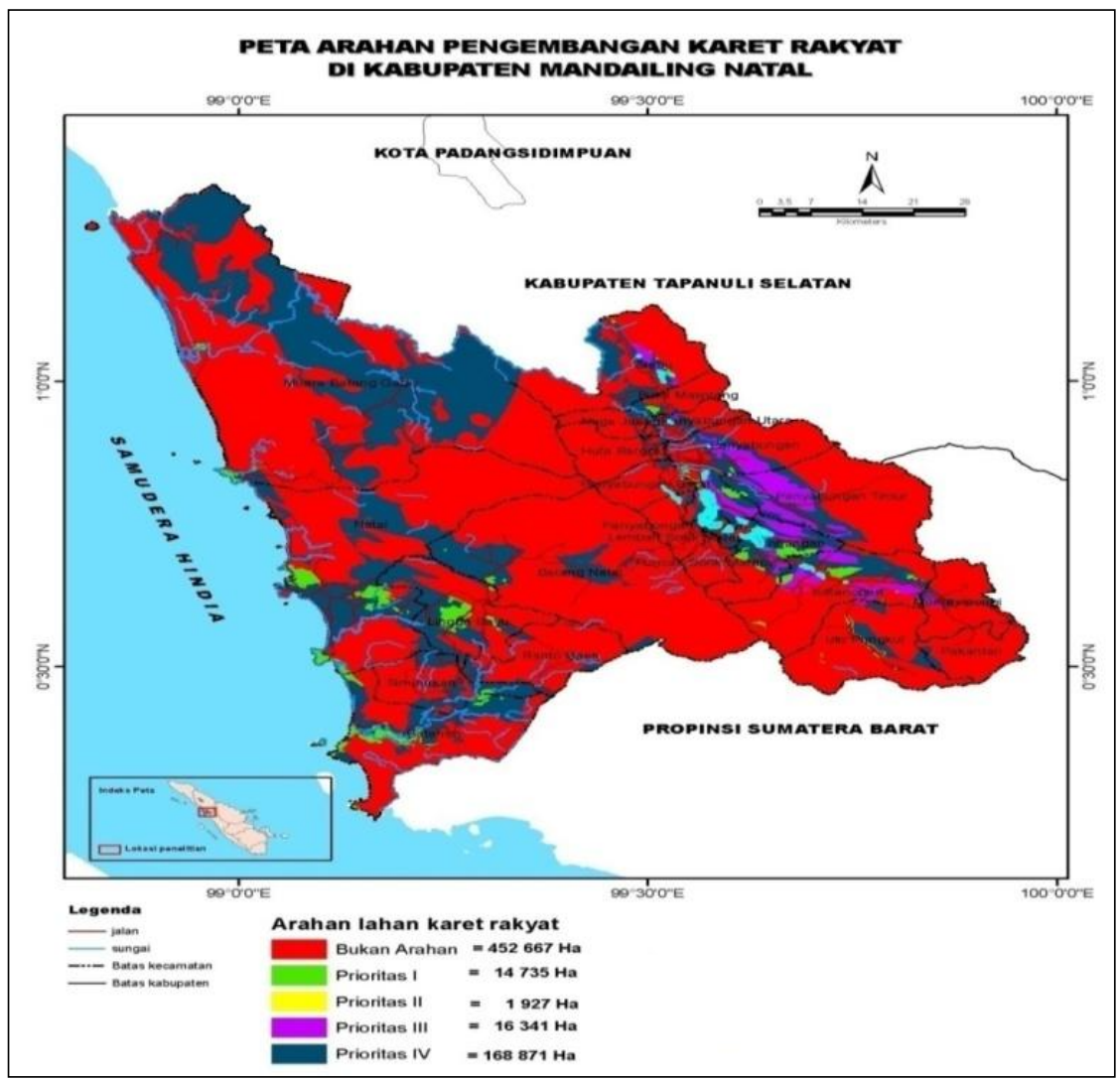

(b)

Gambar 1. Peta kesesuaian lahan karet Kabupaten Mandailing Natal (a) dan Lokasi arahan pengembangan kebun karet rakyat di Kabupaten Mandailing Natal (b) 
Pembuatan peta arahan lokasi pengembangan tanaman karet ini baru sebatas mengarahkan masyarakat bahwa lokasi-lokasi tersebut sesuai secara fisik dan spasial untuk pengembangan tanaman karet, belum mempertimbangkan keberadaan tanaman perkebunan lain di lokasi tersebut atau bukan merupakan pewilayahan komoditas perkebunan. Dalam hal ini masyarakat diberi kesempatan untuk mengambil keputusan sendiri komoditas apa yang akan dikembangkannya. Hal ini merupakan salah satu kelemahan penelitian ini. Dalam penelitian ini, komoditas karet sengaja dijadikan obyek karena tanaman ini merupakan tanaman yang memiliki prospek pasar yang cerah, diminati masyarakat, telah diusahakan secara turun temurun dan merupakan tanaman perkebunan utama di Kabupaten Mandailing Natal.

Arahan kebijakan pengembangan perkebunan karet rakyat di Kabupaten Mandailing Natal berdasarkan hasil analisis yang dilakukan adalah sebagai berikut:

1. Pengembangan tanaman karet rakyat di Kabupaten Mandailing Natal dapat diarahkan ke lahan arahan pengembangan yang telah dibuat seluas 201,875 ha dengan prioritas pengembangan seperti pada Tabel 3 yang secara spasial ditunjukkan pada Gambar 2. Untuk itu diperlukan sosialisasi oleh pemerintah agar masyarakat mengetahui lokasi arahan pengembangan tersebut.

2. Pemerintah perlu membuat kebijakan berupa program percepatan peremajaan karet dengan teknologi budidaya yang dianjurkan.

\section{SIMPULAN}

1. Sebagian besar lahan di Kabupaten Mandailing Natal sesuai untuk budidaya tanaman karet yaitu seluas 460,849 ha $(70.4 \%)$, sedangkan lahan yang tidak sesuai hanya seluas 193,693 ha $(29.6 \%)$.

2. Pengembangan perkebunan karet rakyat di Kabupaten Mandailing Natal dapat diarahkan pada lahan seluas 201,875 ha $(30.8 \%)$. Lahan tersebut tersebar di 23 kecamatan di Kabupaten Mandailing Natal. Kecamatan dengan luasan arahan terbesar terdapat di Kecamatan Muara Batang Gadis. Arahan pengembangan ini bukan berarti menekankan agar keseluruhan luasan tersebut hanya sesuai untuk tanaman karet, namun hanya bersifat arahan agar masyarakat yang berminat untuk mengembangkan tanaman karet dapat menanamnya di areal arahan ini.

\section{SARAN}

1. Pemerintah Kabupaten Mandailing Natal perlu segera merealisasikan rencana pembangunan pabrik pengolahan karet di Kabupaten Mandailing Natal mengingat ketersediaan bahan baku yang cukup besar dan hal ini akan berimplikasi pada peningkatan perekonomian daerah.

2. Pemerintah Kabupaten Mandailing Natal agar lebih meningkatkan peran para penyuluh dan pembentukan kelompok-kelompok tani di masyarakat untuk meningkatkan mutu karet yang dihasilkan dan meningkatkan bargaining position petani dalam pemasaran karet dan mengarahkan petani pada penggunaan klon karet unggul dengan produktivitas tinggi dan teknik budidaya sesuai anjuran.

\section{DAFTAR PUSTAKA}

Boerhendhy, I., C. Nancy, dan A. Gunawan. 2003. Prospek dan potensi pemanfaatan kayu karet sebagai substitusi kayu alam. J. Ilmu \& Teknologi Kayu Tropis, 01: 35-46.

[BPS] Badan Pusat Statistik Mandailing Natal. 2009. Mandailing Natal dalam Angka. Badan Pusat Statistik Kabupaten Mandailing Natal. Panyabungan.

[Ditjenbun] Direktorat Jenderal Perkebunan Departemen Pertanian. 2007. Pedoman Umum Revitalisasi Perkebunan (Kelapa Sawit, Karet dan Kakao). http://www.ditjenbun.deptan.go.id (diakses pada 3 Maret 2007).

[Ditjenbun] Direktorat Jenderal Perkebunan Departemen Pertanian. 2009. Hari Perkebunan 10 Desember, Merajut Sejarah Panjang Perkebunan Indonesia. http//www.ditjenbun.deptan.go.id (diakses pada 14 Januari 2010).

Hardjowigeno, S. dan Widiatmaka. 2007. Kesesuaian Lahan dan Perencanaan Tata Guna Tanah. Departemen Ilmu Tanah dan Sumberdaya Lahan. Fakultas Pertanian - IPB, Bogor.

Sitorus, S.R.P. 2004. Evaluasi Sumberdaya Lahan. Penerbit Tarsito, Bandung. 
